\title{
Isparta yöresi kızılçam meşcerelerinde çap dağılımının örnek alan ă̆aç sayısına göre modellenmesi
}

\author{
Yılmaz Çatal ${ }^{\mathrm{a}, *}$, Siraç Güneş ${ }^{\mathrm{a}}$
}

\begin{abstract}
Özet: Kızılçam (Pinus brutia Ten.) 5.9 milyon hektar yayılışı ile ülkemizde en geniş yayılış alanına sahip asli ağaç türüdür. Bu alan ormanlarımızın \%27'sine karşılık gelmektedir. Meşcere parametrelerinin uygun bir orman yönetimi için doğru tahmin edilmesi gerekir. Ayrıca, ormanların geleceğe yönelik fizibilitesinin yapılmasında çap dağılımları önemli bir meşcere parametresidir. Çap dağılımının şekli meşcere yapısının karakteristiklerinin en önemlilerinden birisidir. Son yıllarda birçok araştırmacı istatistik dağılım modellerini ormancılık alanında kullanmaktadır. Bu çalışmanın amacı, Isparta yöresinde doğal, aynı yaşlı, saf kızılçam meşcerelerinde ağaç sayının çap basamaklarına dağılımının değişik yaş ve bonitet sınıflarında değişimini örnek ağaç sayısı değişimine göre ortaya koyabilmektir. Örnek alanlardan elde edilen verilere Beta, Gamma, Weibull, Normal ve Log-normal istatistik dağılımını esas alan regresyon modelleri uygulanmıştır. Bunun için yörede 6'dan 21'e kadar değişen ağaç sayısına göre çeşitli büyüklüklerde 88 örnek alan alınmıştır. Her istatistik dağılım modeli için doğrusal bir model kurulmuş ve modelin katsayıları çoğul regresyon analizi ile hesaplanmıștır. Regresyon modelinin uygunluğunun tespiti için hesaplanan $\mathrm{F}$ te st değeri ve belirtme katsayısı, Gamma dağılım modeli için en yüksek bulunmuştur $\left(F=55.587 ; p<0.001 ; R^{2}=0.519\right)$. Yörede çap dağılım modellemelerinde Gamma dağılım modelinin kullanılması uygundur.
\end{abstract}

Anahtar kelimeler: Meşcere çap dağılımı, Kızılçam, Bonitet, Meşcere yaşı

\section{Modelling of diameter distribution according to tree numbers in sample area of the Brutian pine stands in Isparta region}

\begin{abstract}
Brutian pine (Pinus brutia Ten.) is the most widely distributed main tree species of Turkey and it covers approximately 5.9 million ha, accounting for $27 \%$ of the Turkey's forests. The stand parameters must be accurately estimated for an appropriate forest management. Besides, it is important to know the stand diameter distribution for the determination of the technique, time and economic feasibility of a stand maintenance treatment. The shape of the diameter distribution is one of the important elements characterising forest stand structure. In recent years, many researches have used the statistical frequency distributions in the field of forestry. Aim of this study, alteration of the diameter distribution by site quality and age, presented by the actual structure of even aged brutian pine stands in the Isparta Forest region, has been related to the models constructed by basing on the distributions of Gamma, Beta, Normal and Weibull. The data used in the computations of models has been obtained different size 88 temporary plots contain from 6 to 21 trees. . A linear model has been constructed for each distribution, and the coefficients in the model have been computed with the help of regression analysis. Besides, standard error and multiple correlation coefficients have also been determined. Later, the estimated values that the determined models gave have been graphically compared with the actual measurements. Gamma Distribution model seems to be more suitable than other distribution models $\left(\mathrm{F}=55.587 ; \mathrm{p}<0.001 ; \mathrm{R}^{2}=0.519\right)$. Gamma distrubution model is usable in the region for diameter distribution model.

Keywords: Stand diameter distribution, Brutian pine, Site index, Stand age
\end{abstract}

\section{Giriş}

Ülkemiz ormancılı politikasının en önemli sorunlarından birisi, en önemli doğal kaynaklarımızdan olan ormanlarda, yetişme ortamı koşullarına uygun ve devamlılık ilkesine bağlı bir işletmecilik yapabilmek, meşcere kalitesi ile verimini yükseltme olanaklarını araştırmak, bu itibarla, asli orman ağaç türlerimizin meşcere kuruluşları, verim güçleri ve büyüme seyirleri hakkında yöresel çalışma yeters izliğidir. Ağaç sayısının yaş ve bonitet s mıflarına göre çap basamaklarına dağılımı bilinerek gelecekteki çap dağılımı ve meşcere hacmi hesaplanabilmektedir (Saraçoğlu, 1988; Borders ve Patters on, 1990).
Çap dağılımları ile ilgili ilk çalışmalar 1883 yılında Gram'ın kayın meşcerelerinin çap dağılımlarını normal dağılıma ve 1898 yılında De Liocourt'un değişik yaşlı meşcerelerde çap dağılımlarını eksponansiyel dağılıma uygun bulduğu çalışmalardır (Packard, 2000). Daha sonraları ise çap dağılımı meşcere yaşı, göğüs yüzeyi, ağaç sayıs1, bonitet endeksi ve derecesi, orta çap ve hacim gibi meşcere elemanları ile ilişkili olduğu belirtilmektedir (Newton vd., 2005).

Meşcerede hacim ve hacim elemanlarına yönelik sonuçların değerlendirilmesinde ağaç sayısı en önemli meşcere elemanıdır. Çünkü meşcerede tüm hacim ve hacim elemanları ağaç sayısına göre değişmektedir. Özellikle, simülasyon modelleri ile meşcerenin tanımlanması ve

\footnotetext{
a Süleyman Demirel Üniversitesi, Orman Fakültesi, 32260, Isparta

@* Corresponding author (İletişim yazarı): yilmazcatal@sdu.edu.tr
}

$\checkmark$ Received (Geliş tarihi): 30.05.2016, Accepted(Kabul tarihi): 04.08.2016
Citation (Atıf): Çatal, Y., Güneş, S., 2016. Isparta Yöresi kızılçam meşcerelerinde çap dağılımının örnek alan ağaç sayısına göre modellenmesi. Turkish Journal of Forestry, 17(2): 166-173. DOI: $10.18182 /$ tif. 37003 
meşcereye ilişkin hacim verimlerinin ortaya koyulmas inda artık çap dağılım modelleri geniş olarak kullanılmaktadır. Ormancıllk planlaması açısından önemli bir bilgi olan ormandan elde edilecek ürün çeşitlerinin belirlenmesi ise, meşcerelerin çap dağılımlarının tahmin edilmesi ile mümkün olabilmektedir. Meşcerede toplamağaç sayısından ziyade hangi çap basamağında kaç tane ağacın olduğunu bilmek ürün ve ürün çeşitlerini ortaya koymada en büyük destekçisi konumundadır (Borders ve Patterson, 1990).

Dünyada ve ülkemizde çap dağılımlarının modellenmesinde Normal, Log-normal, Gamma, Beta, Weibull fonksiyonu gibi çeşitli olasılık yoğunluk fonksiyonları kullanılmaktadır. $\mathrm{Bu}$ dağılımlar meşcerede çap basamaklarına dağılımı yeterli doğruluk düzeyinde tanımladığı ve meşcerenin geleceğine yönelik projeksiyonlar sunabildiği bilinmektedir. Beta dağılımı için Clutter ve Bennet (1965), Mc Gree ve Della-Bianca (1967), Lenhart ve Clutter (1971), Mike vd. (1975), Cao (1997), Lenhart (1972); Gamma dağılımı için Nelson (1964); Weibull dağılımı için Bailey ve Dell (1973), Nepal ve Somers (1992), Cao (1997), Schreuder vd. (1979); Normal dağılım için Clutter ve Bennet (1965) ve Log-normal dağılım için Lappi ve Bailey (1987) çalışmalar yapmış lardır.

Ülkemizde göknar (Abies spp.) meşcerelerinde artım ve büyüme ilişkileri araştırılırken çap dağ 1 ımı denklemlerle ortaya koyulmuştur (Saraçoğlu, 1988). Doğu kayını (Fagus orientalis Lipsky) aynı yaşlı (Carus, 1998) ve değişik yaş 1 (Atıcı, 1998) meşcereleri için çap dağ 11 mm modelleri oluşturulmuştur. Yavuz vd. (2002), diş budak meşcerelerine ilişkin çap dağılımları Weibull Dağılımı yardımıyla belirlenmiş ve bu dağılımın katsayı değerleri ile meşcere yaşı ve bonitet endeksi aras ındaki iliş kiler incelenmiştir. Gül vd. (2005), Karadeniz yöresi değişik yaşlı göknar Sterba (1975)'nın sıklık yarışma değişkenini kullanmışlardır. Çap dağılımının ortaya koyulması amacı ile $\mathrm{G}_{\max }$, göğüs yüzeyi orta ağacının çapı, ağaç sayısı hesaplanmıştır. Kızılçamda 7 ağac1 kapsayacak örnek alanlarda Log-normal olasılik dağ 1 lım fonksiyonu en iyi dağılım sonucunubulduğu ancak küçük örnek alanlarının çap dağılımını tanımlamada yeters iz kaldığg1 görülmüştür (Carus ve Çatal, 2008). Ayrıca ülkemizde Ercanlı ve Yavuz (2010), Kahriman ve Yavuz (2011), Doğdaş (2014)'a ait çap dağılımı makaleleri vardır.

$\mathrm{Bu}$ çalışmanın ilk amacı Isparta yöresinde doğal ve saf kızılçam meşcerelerinde ağaç sayısının çap basamaklarına dağılımının değişik yaş ve bonitet sınıflarında değişimi ortaya koyulmasıdır. Örnek alanlardan elde edilen verilere Beta, Gamma, Weibull, Normal ve Log-normal istatistik dağılımını esas alan regresyon modelleri uygulan mıştır. Her is tatistik dağılım modeli için doğrusal bir model kurulacak ve modelin katsayıları çoğul regresyon analizi ile hes aplanmış, ayrıca, gerçek ve regres yon denkleminden elde edilen değerler grafiksel olarak karşılaştırılmıştır. İkinci amacı ise çap dağ 1 lımının modellenmesinde en uygun örnek alan büyüklüğünün belirlenmesidir. Bu amaçla örnek alan boyutu altı ağaç temel alınarak birer ağaç arttırılarak 21 ağaca kadar büyütülmüştür. Böylece değişik ağaç sayısı içeren örnek alanlar kullanılarak en uygun çap dağılım modelini ortaya koyan ağaç sayısını kapsayan, örnek alan büyüklüğü belirlenmiştir. Böylece, çap dağılımının ortaya koyulmasında uygun ağaç sayısı temelli örnek alan büyüklükleri belirlenmiştir.

\section{Materyal ve yöntem}

\subsection{Materyal}

Çalışma alanı olarak Isparta Orman Bölge Müdürlüğü seçilmiştir. Yörede değişik yükselti $(0-1300 \mathrm{~m})$, bonitet sınıfları (I-V), arazi şekli (yamaç, sırt vb.), gelişim çağı, bakı, yaş ve eğimde doğal ve yapay kızılçam meşcereleri yer almaktadır. Ağaçların büyüme özelliklerinin birbirlerine etkisini ortaya koymak ve kıyas lamak için eşit silvikültürel şartları sağlamak amacıyla olabildiğ ince planlı silvikültürel müdahale görmemiş meşcerelerde çalışma yürütülmüştür.

Orman hasılat çalışmalarında elde edilen verilerin güvenirliği, örnek alanın büyüklüğüile son derece ilişkilidir. Meşcerede örnek alanın büyüklügü belirlenirken örnek alanın meşcerenin özelliklerini yansıtması gerekir. Normal kuruluştaki meşcerede örnek alanın meşcerenin homojenliğini kaybetmeyecek kadar küçük, ağaç sayılarının çap basamaklarına dağılışını yeter güvenle verecek kadar büyük olması ön şart olarak aranmaktadır (Kalıpsı, 1982). $\mathrm{Bu}$ yüzden uygun örnek alan büyüklüğü hasılat araştırmalarında son derece önemlidir. Bruce ve Schumacher (1950), örnek alanların, aynı güvenle bilgi verebilmeleri için eşit büyüklükte olması yerine eşit sayıda ağaç kapsamasının önemli olduğunu bildirmektedir.

Çalışmamızda eşit ağaç sayısını esas alan yöntem uygulanmıştır. Meşcereyi temsil edecek bir merkez nokta belirleyip onu çevreleyen 6 ağaç örnek alan olarak değerlendirilmiş, sonras ında ise ağaç sayıs 1 birer arttırılarak 21 ağaca kadar örnek alanın büyütülmesi ile işlem sonlandırılmıştır. Belirlenen örnek alanlarda tüm komşu ağaçların merkez nokta ile mesafeleri $(\mathrm{cm})$ yatay olarak elektronik Haglöf mesafe ölçer ile belirlenmiştir. Mesafenin belirlenmesinde örnek alan merkezi ile ağaçların gövde eks enleri arasındaki mesafenin ölçümü yapılmıştır.

Örnek alandaki tüm ağaçların göğüs yüksekliğindeki çapları (mm) hassasiyetinde, bonitetin belirlenmesi için bonitet ağaçlarında HaglöfEC elektronik boy ölçer ile $0.1 \mathrm{~m}$ hassasiyetle boylar ölçülmüştür. Örnek alanlarda en az 3 orta ağaçta yaş tespiti yapıııı̧̧ tır. Bonitet sınıfi ve endeksi belirlemede Çatal (2009)'ın tablolarından yararlanılmıştır.

\subsection{Yöntem}

Yirminci yüzyılın ortalarından itibaren ormancılıkta çap dağılımlarının modellenmesinde, olasılik yoğunluk fonksiyonları kullanılmaya başlanmıştır. İlk olarak, Clutter ve Bennet (1965), çap dağılımlarını, dört parametreli beta fonksiyonu ile modellemişlerdir (Packard, 2000). Daha sonralar1 Normal, Lognormal, Gamma, Beta, Johnson's SB, ve Weibull fonksiyonu gibi çeşitli olasılık yoğunluk fonksiyonları kullanılmaktadır. Çap dağılım parametreleri değişik yöntemler kullanılarak tahmin edilebilmektedir. Bazı araştırmacılar tarafindan parametre tahmini için moment tabanlı yaklaşım önerilmektedir (Lindsay vd., 1996; Merganic ve Sterba, 2006). Pratik araştırma maksimum olasılık tahminleri uygulamaları ile tanımlanabilmektedir (Somers vd., 1980). Bu çalışmada da önce dağılım modellerinin elde edilmesi ve daha sonra regresyon katsayılarının hesaplanış tarzını, Loetsch vd. (1973) tarafindan Beta dağılımına uyguladığ hesap biçimi ile gösterilmesi amaçlanmıştır. Çalışmamızda da, değişik yaş ve bonitetlerdeki kızılçam meşcerelerinde 
ağaç sayısının çap basamaklarına dağılımlarının ortaya konulmasında aynı yöntem esas alınmıştır. Beta dağılımı yan1 sira, Normal, Log-normal, Gamma ve Weibull dağılımlarından türetilen modeller bilgisayarda veri kütükleri yardımıyla incelenmiştir.

\subsection{Verilerin istatistik analizi}

Çalışmamızda, örnek noktalardan elde edilen verilerin, Beta, Gamma, Weibull Normal ve Log-normal istatistik dağılımını esas alan regresyon modellerinin katsayılarının çoğul regresyon analizi ile hesaplanmas inda ve regresyon modelinin uygunluğunun tespiti için $F$ test değerinin bulunmasinda SPSS (Statistical Package for Social Sciences) Ver. 20.0 is tatistik paket programı kullanılmıştır. Ayrica, regresyon modelinden elde edilen değerler grafiklerle ortaya koyulmuştur.

Üssel fonksiyonda en küçük kareler yöntemini uygulayabilmek için fonksiyon logaritması alınarak doğrusal forma dönüştürülmüş, işlemler onun üzerine yürütülmüştür. Logaritma alarak hesap yapılması nedeniyle oluşan sistematik hatanın giderilmesi için, antilogaritma alınarak bulunan değerlerin bir düzeltme faktörü ile çarpılmas1 gerekir. $\mathrm{Bu}$ amaçla düzeltme faktörü $\left[\exp \left(0.5 * \mathrm{Se}^{2}\right)\right]$ denklemi ile hesaplanmıştır. Model ile elde edilen değerler en son düzeltme faktörü ile çarpılarak sunulmuştur (Husch vd., 1963; Frrat, 1973).

\section{Araştırma bulguları}

Çalışma kapsamında alınan örnek alanların 21 ağaçlık büyüklük için hacim ve hacim elemanlarına ilişkin bazı is tatistikler Çizelge 1'de verilmiştir.

Aynı yaşlı meşcerlerde çap dağılımları normal veya normale yakın dağılım göstermektedir. $\mathrm{Bu}$ çap dağılımının ortaya konulması için Beta, Normal, Log-normal, Gamma ve Weibull gibi istatistik dağılımlardan yararlanılmaktadır. Söz konusu çap dağılım modellerine ilişkin hesap ve değerlendirmeler aşağıda verilmiştir. Bu amaçla oluşturulan is tatis tik dağılımları temel alan regresyon modelleris sras ıyla denenmiştir.

Çizelge 1. Örnek alanlarının bazı meşcere hacim ve hacim eleman 1 is tatis tikleri

\begin{tabular}{ccrrrrr}
\hline Değişken & $\mathrm{N}$ & Min. & Max. & $\begin{array}{c}\text { Aritmetik } \\
\text { ortalama }\end{array}$ & $\begin{array}{c}\text { Standart } \\
\text { sapma }\end{array}$ & $\begin{array}{c}\text { Varyasyon } \\
\text { yüzdesi }\end{array}$ \\
\hline $\begin{array}{c}\text { Meşcere } \\
\text { yaşı (y1) }\end{array}$ & 88 & 21 & 87 & 51.2 & 15.8 & 30.9 \\
\hline $\begin{array}{c}\text { Ust boy } \\
(\mathrm{m})\end{array}$ & 88 & 8.3 & 32.3 & 17.8 & 4.3 & 24.2 \\
\hline $\begin{array}{c}\text { Orta çap } \\
(\mathrm{cm})\end{array}$ & 88 & 10.6 & 50.3 & 28.5 & 9.4 & 33.0 \\
\hline $\begin{array}{c}\text { Ağaç Say1s1 } \\
(\text { ad/ha) }\end{array}$ & 88 & 199 & 1920 & 610.6 & 403.5 & 66.1 \\
\hline $\begin{array}{c}\text { Göğüs } \\
\text { Yüzeyi } \\
(\mathrm{m} \text { /ha) }\end{array}$ & 88 & 10.3 & 77.5 & 31.1 & 13.2 & 42.5 \\
\hline $\begin{array}{c}\text { Bonitet } \\
\text { Endeksi } \\
(\mathrm{m})\end{array}$ & 88 & 13.0 & 35.7 & 21.6 & 4.6 & 21.3 \\
\hline
\end{tabular}

\subsection{Normal dă̆ılım}

Gauss dağılımı veya Gauss tipi dağılım olarak isimlendirilen normal dağılım birçok alanda pratik uygulaması olan, çok önemli bir sürekli olas ılık dağılımdır. $\mathrm{Bu}$ dağlım iki parametreyle tam olarak tanımlanabilir: Bunlar konum gösteren ortalama ( $\mu$, aritmetik ortalama) ve ölçek gösteren varyans $\left(\sigma^{2}\right.$-yayılım)'dır (Bailey ve Dell, 1973).

$$
f(x)=\frac{1}{\sigma \sqrt{2 \pi}} \exp \left\lfloor-\frac{1}{2}\left(\frac{x-\mu}{\sigma}\right)\right\rfloor
$$

Normal dağ 1 lım modeli için $\mathrm{n}=e^{\left(a+b . d+c \cdot d^{2}\right)}$ fonksiyonu esas alınacaktır. Logaritma dönüşümünü yapıp, bonitet endeksi ve yaşa göre aşağıdaki doğrusal model türetilmiştir.

$$
\begin{aligned}
& \ln (n)=\beta_{0}+\beta_{1} \cdot B E+\beta_{2} \cdot t+\beta_{3} \cdot B E \cdot t+\beta_{4} \cdot d+\beta_{5} \cdot B E \cdot d+\beta_{6} \cdot t \cdot d+ \\
& \beta_{7} \cdot \text { BE.t.d }+\beta_{8} \cdot d^{2}+\beta_{9} \cdot B E \cdot d^{2}+\beta_{10} \cdot t \cdot d^{2}+\beta_{11} \cdot B E \cdot t \cdot d^{2}
\end{aligned}
$$

Normal dağılım modeli kullanılarak çap dağılım modelinin geçerliliği test edilmiş, en uygun örnek alan büyüklüğü 17 ağaç kapsayacak örnek alan olduğu belirtme katsayısı ve F değeri ile bulunmuştur. Normal dağılım için uygun bulunan bu örnek alan büyüklüğ̈̈ için elde edilen is tatistikler ve katsayılar Çizelge 2'de verilmiş tir.

Yine söz konusu modelin verilere uygunluğu denetlenmiş ve 0.001 önem düzeyi için, bulunan $F_{\text {test }}$ değeri,

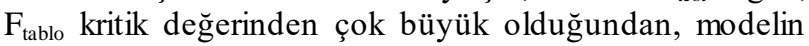
verilere uygun olduğu kabul edilmiştir. Modelin belirtme katsayıs1 0.481 olarak bulunmuştur. Ayrıca bu ağaç sayıs1 için F değeri 47.707 olarak tespit edilmiştir.

\subsection{Beta dă̆ılımı}

Beta dağ ${ }_{1}$ ımı modeli için; $n=k \cdot\left(d-d_{\text {min }}\right)^{\alpha} \cdot\left(d_{\max }-d\right)^{\beta}$ modeli es as alınmıştır. Bu modele logaritma dönüşümü uygulanarak $\ln (\mathrm{n})=\ln (\mathrm{k})+\alpha \cdot \ln \left(\mathrm{d}-\mathrm{d}_{\mathrm{min}}\right)+\beta \cdot \ln \left(\mathrm{d}_{\max }-\mathrm{d}\right)$ eşitliği elde edilmiş tir. Burada katsayılar Bonitet endeksi (BE) ve yaşa (t) bağlı olarak değişim göstermektedir. Modelde yaşın doğrusal olarak etkilediği düşünülürse, model $\left(\ln (k)=a_{0}, \alpha=a_{1}\right.$ ve $\left.\beta=a_{2}\right) \quad$ alınırsa model; $\ln (n)=a_{0}+a_{1} \cdot \ln \left(d-d_{\min }\right)+a_{2} \cdot \ln \left(d_{\max }-\right.$ d) $+\left[a_{3}+a_{4} \cdot \ln \left(d-d_{\text {min }}\right)+a_{5} \cdot \ln \left(d_{\max }-d\right)\right] . t$ şeklinde yazilabilir. $B u$ modeldeki katsayılarında, $\mathrm{a}_{0}=\beta_{0}+\beta_{1}$. BE, $\mathrm{a}_{1}=\beta_{4}+\beta_{5}$. BE, $a_{2}=\beta_{8}+\beta_{9} . B E, \quad a_{3}=\beta_{2}+\beta_{3} . B E, \quad a_{4}=\beta_{6}+\beta_{7} . B E, \quad a_{5}=\beta_{10}+\beta_{11}$. BE biçiminde bonitet endeksi ile iliş̧kili olduğu düşünülürse, model bu değişkenleri içeren doğrusal bir şekilde denklem 3 elde edilir.

Çizelge 2. Normal dağılım fonksiyonuna ilişkin bazı is tatistik ve katsayılar

\begin{tabular}{lllllll}
\hline \multicolumn{2}{c}{ Istatistikler } & \multicolumn{1}{c}{ Katsayılar } & \multicolumn{2}{c}{ Katsayılar } & \multicolumn{2}{c}{ Katsayılar } \\
\hline $\mathrm{R}^{2}:$ & 0.481 & $\beta_{0}: 13.441726$ & $\beta_{4}:$ & -0.308662 & $\beta_{8}:$ & 0.004406 \\
$\mathrm{R}:$ & 0.693 & $\beta_{1}:-0.210235$ & $\beta_{5}:$ & 0.009816 & $\beta_{9}:$ & -0.000214 \\
$\mathrm{R}$ düz: & 0.471 & $\beta_{2}:-0.088311$ & $\beta_{6}:$ & 0.002712 & $\beta_{10}:$ & -0.000050 \\
$\mathrm{~F}:$ & $47.707^{* * *}$ & $\beta_{3}:-0.000295$ & $\beta_{7}:$ & $0 *$ & $\beta_{11}:$ & 0.000002 \\
\hline ***p$<0,001,{ }^{*}$ Değişken, regresyon analizi sırasında SPSS programınca \\
\multicolumn{2}{c}{ önemsiz bulunmuş ve hesaplanmamıştır. }
\end{tabular}


$\ln (n)=\beta_{0}+\beta_{1} \cdot B E+\beta_{2} \cdot t+\beta_{3} \cdot B E \cdot t+\beta_{4} \cdot \ln \left(d-d_{\text {min }}\right)+\beta_{5} \cdot B E \cdot \ln (d-$ $\left.\mathrm{d}_{\text {min }}\right)+\beta_{6} \cdot \operatorname{tr} \cdot \ln \left(\mathrm{d}-\mathrm{d}_{\min }\right)+\beta_{7} \cdot \mathrm{t} \cdot \mathrm{BE} \cdot \ln \left(\mathrm{d}-\mathrm{d}_{\min }\right)+\beta_{8} \cdot \ln \left(\mathrm{d}_{\max }-\mathrm{d}\right)+$ $\beta_{9} \cdot B E \cdot \ln \left(d_{\max }-d\right)+\beta_{10} \cdot t \cdot \ln \left(d_{\max }-d\right)+\beta_{11} \cdot B E \cdot t \cdot \ln \left(d_{\max }-d\right)$

Beta dağılım modeli için elde edilen istatistikler incelendiği zaman bağlı değişkenin serbest değişkenlere bağlılığını ölçen istatistik belirtme katsayısı birer ağaç arttırılarak oluş turulan farklı büyüklükte örnek alanlar için 8 ağaçlık örnek alan büyüklüğü için elde edilmiştir. Çap dağılım modellerinden Beta Dağılım modeli için geliştirilen model kullanılarak regresyon analizinde elde edilen bazı is tatistik ve katsayılar Çizelge 3'de verilmiştir.

Yine söz konusu modelin verilere uygunluğu denetlenmiş ve 0.001 önem düzeyi için, bulunan Ftest değeri, Ftablo kritik değerinden çok büyük olduğundan, modelin verilere uygun olduğu kabul edilmiştir. Beta dağılım modeli \%50,9 oranında çap dağılımını yaş ve bonitete göre açıklayabilmektedir.

\subsection{Gamma dă̆ılımı}

Gamma dağılıma ilişkin olasılık yoğunluk fonksiyonu aşağıdaki gibidir (Nelson, 1964).

$$
f(x)=\mathrm{a} \cdot e^{-\beta \cdot x}
$$

Gamma dağılım modeli için; $\mathrm{n}=\mathrm{a} . \mathrm{d}^{\mathrm{b}} . \mathrm{e}^{(c . d)}$ modeli esas alınacaktır. Buradan doğrusal forma dönüştürüp bonitet endeksi ve yaşa göre türeterek denklem 5 elde edilmiştir. Regresyon analizi sonucu model is tatistikleri ve katsayılar Çizelge 4'de verilmiştir.

$\ln (n)=\beta_{0}+\beta_{1} \cdot B E+\beta_{2} \cdot t+\beta_{3} \cdot B E \cdot t+\beta_{4} \cdot d+\beta_{5} \cdot B E \cdot d+\beta_{6} \cdot t \cdot d+\beta_{7} \cdot$ BE.t.d $+\beta_{8} \cdot \ln d+\beta_{9} \cdot$ BE. $\ln d+\beta_{10} \cdot$ t.lnd $+\beta_{11} \cdot$ BE.t.lnd

Çizelge 1. Beta dağılım fonksiyonuna ilişkin bazı istatistik ve katsayılar

\begin{tabular}{|c|c|c|c|c|}
\hline Ist & atistikler & Katsayılar & Katsayılar & Katsayılar \\
\hline$\overline{\mathrm{R}^{2}:}$ & 0.509 & $\beta_{0}: 11.46908$ & $\beta_{4}:-0.553341$ & -0.446756 \\
\hline $\mathrm{R}:$ & 4 & $\beta_{1}:-0$. & $\beta_{5}:-0$. & $\beta_{9}:$ \\
\hline $\mathrm{R}_{\text {düz: }}:$ & 0.487 & -0.061603 & -0.004766 & $\beta_{10}:$ \\
\hline F: & $23.385^{* \pi *}$ & 0.000675 & 0.000611 & -0.000067 \\
\hline
\end{tabular}

Çizelge 4. Gamma dağılım fonksiyonuna ilişkin bazı is tatistik ve katsayılar

\begin{tabular}{llllll}
\multicolumn{2}{c}{ Istatistikler } & \multicolumn{1}{c}{ Katsay1lar } & \multicolumn{1}{c}{ Katsay1lar } & \multicolumn{2}{c}{ Katsay1lar } \\
\hline $\mathrm{R}^{2}: 0.519$ & $\beta_{0}: 15.59452$ & $\beta_{4}:-0.01959$ & $\beta_{8}:$ & -2.03731 \\
$\mathrm{R}:$ & 0.720 & $\beta_{1}:-0.283661$ & $\beta_{5}:-0.004998$ & $\beta_{9}:$ & 0.095738 \\
$\mathrm{R}_{\text {düz: }}$ & 0.510 & $\beta_{2}:-0.059997$ & $\beta_{6}: 0.000292$ & $\beta_{10}:$ & $0 *$ \\
$\mathrm{~F}:$ & $55.587 * * *$ & $\beta_{3}:-0.005979$ & $\beta_{7}: 0.000007$ & $\beta_{11}: 0.002058$ \\
\hline
\end{tabular}

Örnek alan büyüklüğübirer ağaç arttırılarak oluşturulan farklı büyüklükte örnek alanlar için Gamma dağılım modeli için istatistikler incelendiği zaman en yüksek belirtme katsayısı ve $\mathrm{F}$ değeri 17 ağaç için elde edilmiştir. $\mathrm{Bu}$ değerler kullanılarak kızılçam için \%51,9 oranında yaş ve bonitet endeks değeri kullanılarak çap basamaklarına dağılımı elde edilebilir.

\subsection{Weibull dağılımı}

Weibul dağılımı esnek bir dağılım modeli olarak bilinmekte ve çap dağılımlarını modellemede değişik ağaç türleri için uygun olduğu belirtilmektedir (Somers vd., 1980). Genelde yapılan geçici örnek alana ilişkin çap modelleri yanı sıra periyodik ölçümler ile devamlı deneme alanlarında çap dağılımları modellenene çalışmalarda vardır (Nepal ve Somer, 1992).

Weibull olasılık dağılımı fonksiyonu, değişik özeliklerdeki meşcerelerde çeşitli şekiller alabilmekte ve çap dağ 1 lımının yaklaşı olarak değerlerini verebilmektedir (Bailey ve Dell, 1973). Birçok meşcere özelliklerinin tanımlanmasında elastikiyetinden dolayı, çap dağılımı ve has 1lat modellerinde Weibull olasılık dağılım fonksiyonu kullanılabilmektedir (Zarnoch vd., 1991). Weibull dağglım modeli denklem 6'da verilmiştir.

$$
f(x)=\left(\frac{a \cdot x^{a-1}}{\beta^{a}}\right) \exp \left[-\left(\frac{x}{\beta}\right)^{a}\right] \alpha, \beta, x>0
$$

Weibull dağılım modeli için; $\mathrm{n}=\mathrm{k} \cdot \mathrm{d}^{\alpha} \cdot \mathrm{e}^{(\beta . d)^{\varphi}}$ fonksiyonu esas alınacaktır. Fonksiyonun logaritması alındı ̆̆ında $\ln (\mathrm{n})=\ln (\mathrm{k})+\alpha \cdot \ln (\mathrm{d})+\beta \cdot \mathrm{d}^{\varphi}$ olur. Eşitliğin son terimi Mac Loren serisine açlabilir. Buna göre, bu ifade $\ln (\mathrm{n})=\beta_{0}+\beta_{1} \cdot \ln (\mathrm{d})+\beta_{2} \cdot d+\beta_{3} \cdot \mathrm{d}^{2}+\beta_{4} \cdot \mathrm{d}^{3}$ biçiminde yazılabilir. $\mathrm{Bu}$ model Weibull fonksiyonuna yaklaşı değerler verebileceğinden çap dağılımının tespitinde kullanılması uygun görülmüştür. Bu modele yaş ve bonitet endeksini sokularak aşağıdaki doğrusal model denklem 7 elde edilir.

$$
\begin{aligned}
& \ln (n)=\beta_{0}+\beta_{1} \cdot B E+\beta_{2} \cdot t+\beta_{3} \cdot B E \cdot t+\beta_{4} \cdot \ln (d)+\beta_{5} \cdot B E \cdot \ln d+ \\
& \beta_{6} \cdot \ln \left(\mathrm{ln}(\mathrm{d})+\beta_{7} \cdot B E \cdot t \cdot \ln (d)+\beta_{8} \cdot d+\beta_{9} \cdot B E \cdot d+\beta_{10} \cdot t \cdot d+\right. \\
& \beta_{11} \cdot B E \cdot t \cdot d+\beta_{12} \cdot d^{2}+\beta_{13} \cdot B E \cdot d^{2}+\beta_{14} \cdot t \cdot d^{2}+\beta_{15} \cdot t \cdot B E \cdot d^{2}+ \\
& \beta_{16} \cdot d^{3}+\beta_{17} \cdot B E \cdot d^{3}+\beta_{18} \cdot t \cdot d^{3}+\beta_{19} \cdot B E \cdot t \cdot d^{3}
\end{aligned}
$$

Son doğrusallaştırılmış denklem kullanılarak çap dağılımları ortaya koyulmaya çalışılmıştır. Weibull dağılım modeli çap dağılımının modellenmesinde geniş kullanım

\begin{tabular}{|c|c|c|c|c|c|c|c|c|c|c|c|}
\hline \multicolumn{2}{|c|}{ Istatistikler } & \multicolumn{2}{|r|}{ Katsayılar } & \multicolumn{2}{|c|}{ Kat sayılar } & \multicolumn{2}{|c|}{ Katsayılar } & \multicolumn{2}{|c|}{ Kat sayılar } & \multicolumn{2}{|c|}{ Kat sayılar } \\
\hline $\mathrm{R}^{2}:$ & 0.506 & $\beta_{0}:$ & 10.610784 & $\beta_{4}:$ & -0.236820 & $\beta_{8}:$ & -0.066870 & $\beta_{12}:$ & $0^{*}$ & $\beta_{16}:$ & -0.000010 \\
\hline $\mathrm{R}$ & 0.711 & $\beta_{1}$ : & -0.203028 & $\beta_{5}:$ & 0.121646 & $\beta_{9}:$ & -0.011542 & $\beta_{13}$ : & $0 *$ & $\beta_{17}:$ & 0.000002 \\
\hline $\mathrm{R}_{\text {düz: }}$ & 0.491 & $\beta_{2}$ : & 0.183703 & $\beta_{6}:$ & -0.097315 & $\beta_{10}:$ & 0.003677 & $\beta_{14}$ : & $0 *$ & $\beta_{18}$ : & $0 *$ \\
\hline $\mathrm{F}:$ & $33,731 * * *$ & $\beta_{3}$ : & -0.016174 & $\beta_{7}:$ & 0.005252 & $\beta_{11}:$ & $0 *$ & $\beta_{15}$ : & -0.000001 & $\beta_{19}:$ & $0 *$ \\
\hline
\end{tabular}
alanına sahip, esnek bir modeldir. Çalışma kapsamında da bu model kullanılarak yapılan regresyon analizi sonucunda elde edilen bazı katsayı ve istatistikler Çizelge 5'de verilmiştir.

Çizelge 2. Weibull dağılım fonksiyonuna ilişkin bazı is tatistik ve katsayılar 
Örnek alan büyüklüğü birer ağaç arttırılarak oluş turulan farklı büyüklükte örnek alanlar için Weibull dağılım modeli için yapılan regresyon analizi sonucunda en yüksek belirtme katsayıs1 ve F değeri 15 ağaçlık örnek alan büyüklüğünde elde edilmiştir. Yaş ve bonitet endeksi değerine göre çap basamaklarındaki ağaç sayısının tanımlanma oranının \%50.6, F değeri de 33.731 bulunmuştur.

\subsection{Log-normal dă̆ılımı}

Log-normal dağılıma ilişkin olasılık yoğunluk fonksiyonu denklem 8'deki gibidir (Baley ve Dell, 1973).

$$
f(x)=\frac{\exp \left[-\frac{1}{2}\left(\frac{\ln (x-\alpha)-\mu}{\sigma}\right)^{2}\right]}{\sigma(x-\alpha) \sqrt{2 \pi}}
$$

$\mathrm{Bu}$ dağ 1 lım modeli için; $\mathrm{n}=\mathrm{e}^{\left(a+b \cdot \ln d+c \cdot \ln ^{2} . d\right)}$ fonksiyonu esas alınacaktır. Logaritma dönüşümünü yapıp, bonitet endeksi ve yaşa göre doğrusal model olarak denklem 9 türetilmiştir.

$\ln (n)=\beta_{0}+\beta_{1} \cdot B E+\beta_{2} \cdot t+\beta_{3} \cdot B E \cdot t+\beta_{4} \cdot \ln (d)+\beta_{5} \cdot B E \cdot \ln (d)+$ $\beta_{6} \cdot \operatorname{t} \cdot \ln (\mathrm{d})+\beta_{7} \cdot$ BE.t. $\ln (\mathrm{d})+\beta_{8} \cdot \ln ^{2}(\mathrm{~d})+\beta_{9} \cdot \mathrm{BE} \cdot \ln ^{2}(\mathrm{~d})+\beta_{10} \cdot \mathrm{t} \cdot \mathrm{l}$ $\mathrm{n}^{2}(\mathrm{~d})+\beta_{11}$.BE.t. $\ln ^{2}(\mathrm{~d})$

Tüm modellerde $\beta_{0}, \beta_{1}, \ldots ., \beta_{11}=$ katsayıları, $B E=$ meșcere bonitet endeksini (m) $\mathrm{t}=$ meş cere yaşını (yıl), $\ln =\mathrm{e}$ tabanında (doğal) logaritmayı (e=2.71828), $\mathrm{d}_{\min }=$ minimum çap1, $\mathrm{d}_{\max }=$ maks imum çap 1 ifade etmektedir.

Log-normal dağılım fonksiyonu için yapılan regresyon analizi sonucunda elde edilen bazı katsay1 ve istatistikler aşağıda verilmiştir.

Örnek alan büyüklüğü birer ağaç arttırılarak oluşturulan farklı büyüklükte örnek alanlar için Log-normal dağılım modeli ile 17 ağaçlık örnek alan büyüklüğünün yeterli olduğu ve bonitet endeksi ile yaş kullanılarak çap basamaklarındaki ağaç sayısının $\% 48.7$ oranında tanımlandığ 1 görülmüştür.

Çizelge 3. Log-Normal dağılım fonksiyonuna ilişkin bazı is tatistik ve katsayılar

\begin{tabular}{|c|c|c|c|}
\hline İstatistikler & Katsayılar & Katsayılar & Katsayılar \\
\hline$\overline{\mathrm{R}^{2}: 0.487}$ & $\beta_{0}: 7.395695$ & $\beta_{4}:-0.0775$ & 0.13798 \\
\hline $\mathrm{R}: 0.698$ & $\beta_{1}:-0.1174$ & $\beta_{5}$ : & $\beta_{9}:$ \\
\hline $\mathrm{R}_{\text {düz: }}: 0.478$ & $\beta_{2}: 0.006518$ & $\beta_{6}:$ & $\beta_{10}:-0$. \\
\hline $\mathrm{F}: 48.979 * * *$ & $\beta_{3}:-0.00808$ & $\beta_{7}: 0 *$ & $\beta_{11}: 0.000823$ \\
\hline
\end{tabular}

\section{6. Çap Dă̆glım Modellemesinde Uygun Örnek Alan İçin Ăgaç Sayısı}

Ülkemizde orman kaynaklarımızdan ekonomik, sürekli ve verimli bir şekilde faydalanabilmek için, meşcerenin hacim elemanları ve hacmi gerçeğe en yakın ölçüde tahmin etmek gerekmektedir. Ormanlara yapılan silvikültürel müdahalelerin zamanı, sıklığ 1 ve ekonomik açıdan uygunluğunun belirlenebilmesi için meşceredeki bireylerin çap basamaklarına dağılımını etkileyen faktörlerin bilinmesi gereklidir.

Ínceleme konusu olarak alınan modellerin çoğul regresyon analizi ile aynı yaş 1 kızılçam meşcereleri için en iyi uyum gösteren modelin Gamma dağılım modeli olduğu, bu dağılım modelinde 17 ağaçlık örnek alan büyüklüğünün ideal olduğu, belirtme katsayısı yüksek ve regresyona ait $\mathrm{F}$ test değerinin $(55.587 * * *)$ daha büyük olmasindan anlaşılmaktadır. Bu model ile herhangi bir yaş ve bonitet sınıfindaki meşcerelerde ağaçların çap basamaklarına dağılımını izlemek mümkündür.

Meşcere içinde çap dağılımı yanıs ıra bu çap dağılımının meşcere yaşı ve bonitet endeksine göre minimum ve maksimum noktalarının da ortaya koyulması gerekmektedir. $\mathrm{Bu}$ amaçla yaş ve bonitet endeksine göre maksimum ve minimum çap değerlerinin hesaplanmasında büyüme eğrisini esas alan, korelasyon katsayısı ve F değeri yüksek çıkan denklem 10 olarak bulunmuştur.

$$
d_{\text {min } / \text { mak }}=\frac{t^{2}}{\left(\beta_{0}+\beta_{1} * t+\beta_{2} * t^{2}\right)+\left(\beta_{3}+\beta_{4} * t+\beta_{5} * t^{2}\right) B E}
$$

Modele ilişkin yapılan regresyon analizi sonuçları Çizelge 7'de verilmiştir.

Çap dağılımın modellenmesinde en uygun model olarak bulunan Gamma dağılım modeli için ağaç sayısının çap basamaklarına dağılımı şekil olarak çizilerek Şekil 1'de verilmiştir.

Şekil 1'den görüleceği gibi Gamma dağılım modeli için değişik yaş bas amakları için çap dağılımları en düşük çap ile en yüksek çap değeri arasında verilmiştir. Yaş ile birlikte ağaç sayısı azalmakta, buna karşın çap basamaklarındaki ağaçların ise sağa doğru kayarak daha kalın bireyler yer aldığ 1 görülmektedir. Yine bonitet endeksi arttıkça ağaçlarm çap basamaklarındaki birey sayıları azalmaktadır. $\mathrm{Bu}$ azalma iyi bonite sahip meşcerelerde daha çok olmaktadır. Bonitet iyileş tikçe ağaçlar arası rekabet artması sonucunda ağaç sayısının azalması daha çok olmaktadır.

Çizelge 4. Minimum ve maksimum çap değerleri regresyon analizi sonuçları

\begin{tabular}{lcccccccccc} 
& $\mathrm{R}$ & $\mathrm{R}^{2}$ & $\mathrm{R}_{\mathrm{düz}}$ & $\mathrm{F}$ & $\beta_{0}$ & $\beta_{1}$ & $\beta_{2}$ & $\beta_{3}$ & $\beta_{4}$ & $\beta_{5}$ \\
\cline { 2 - 9 } $\mathrm{d}_{\max }$ & 0.923 & 0.851 & 0.842 & $93.897 * * *$ & 144.0974 & -2.3071 & 0.0232 & -5.2897 & 0.1034 & -0.0004 \\
$\mathrm{~d}_{\min }$ & 0.812 & 0.659 & 0.638 & $30.976 * * *$ & 245,8422 & -1.2455 & 0.0369 & -11.9572 & 0.2114 & -0.0016 \\
\hline
\end{tabular}



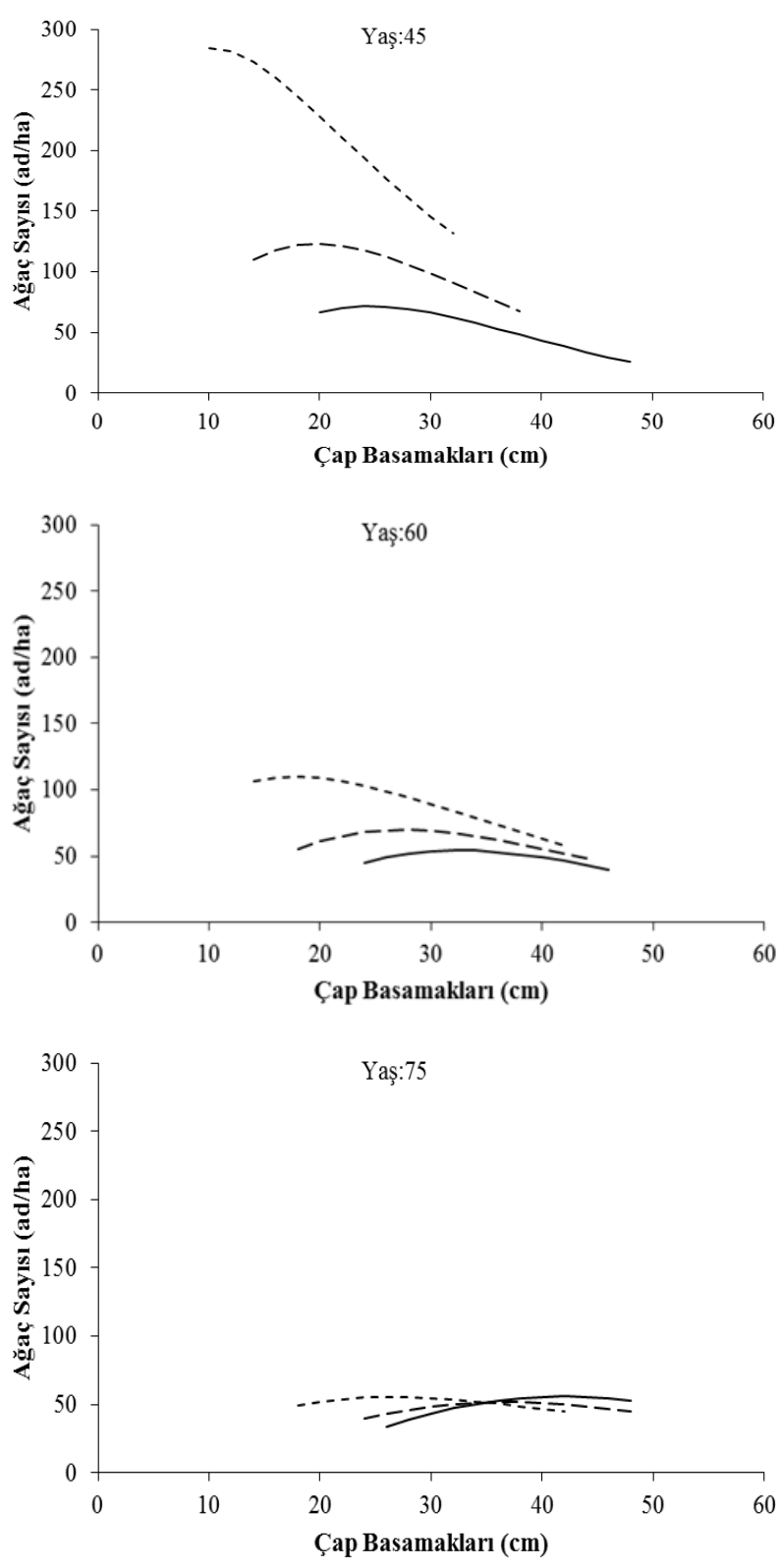

Şekil 1. Gamma dağılım modeli ile değişik yaşlarda ağaçların çap dağılımları(BE: Bonitet Endeksleri)

\section{Sonuç ve öneriler}

Bu çalışmada, Isparta Orman Bölge Müdürlüğü sınırları içeris inde yer alan aynı yaş 1 , safve doğal yoldan gelmiş ve llımlı müdahale görmüş kızılçam saf meşçerelerinin meşcerelerinde ağaçların çap basamaklarına göre değişimi modellenmiştir. Meşcere sıklı̆̆ının bir değişken olarak kullanılmadığı kızılçam meşcereleri için oluşturulan çap dağılım modeline iliş kin aşağıdaki sonuçlar elde edilmiştir.

$\mathrm{Bu}$ çalışmada elde edilen sonuçlar genel hasılat kurallarına uygun olarak ilk yaşlarda sivritepeliçan eğrisine yakın bir dağılım bulunmuştur. Yaşın ilerlemesi ile bu dağılım daha basık bir şekil almıştır. Yaş ilerledikçe ve bonitet iyileştikçe ağaçlar arası rekabetin azalmasından dolayı daha yatay bir eğrinin oluştuğu görülmüştür.

Bir ağacin bulunduğu sosyal sinıf onun gelecek periyotlarda yaşama şansını da büyük ölçüde etkilemektedir. Iş $1 \mathrm{k}$ ağaçlarının oluş turduğu meşcerelerde boyca geri kalmış bireyler kısa bir zaman içerisinde meșcereden kuruyarak ayrılmak durumunda kalmaktadır. Meşcere yaşı ilerledikçe, ağaç sayısı ilk önce hızl, sonra yavaşlayan bir hızla azalmaktadır. Hayat mücadelesi iyi bonitetlerde erken başlayıp erken bitmekte, kötü bonitetlerde ise ileri yaşlara kadar hızını azaltmamaktadır. Çalışmamız kapsamında da bu şekilde elde edilen dağılım eğrileri net olarak görülmüştür.

Aynıyaşlı, safve doğal kızılçam meşcerelerinden alınan örnek alanlara ait çap dağ 1 ım değerlerini sağa çarpık çan eğrisi biçiminde olup Gamma dağ 1 lımına benzemektedir. $\mathrm{Bu}$ durum kızılçamın bir miktar gölgeye dayanma kabiliyetinde olduğunu bize göstermektedir.

Elde edilen dağılım modellerinin istatistikleri incelenince yaş ve bonitet endeksi $\% 52$ oranında çap dağılımını tanımlayabilmektedir. $\mathrm{Bu}$ dağılımların değişkenleri arasına sıklık derecesi eklendiği zaman daha yüksek bir tanımlama elde edileceği kes indir. Bu amaçla çap dağ 1 lımı modeline sıklık derecesideğişkeninin de sokulması gerekir.

Her çap dağılım modeli ayrı ayrı değişik örnek alan büyüklüğüne göre test edilmiştir. Kızılçam meşcereleri için kullanılan dağılım modellerinden Beta dağ 1 lım modeli için 8 ağaçlık örnek alan büyüklüğü, Weibul dağılım modeli içinde 15 ağaçlık örnek alan büyüklüğü, Normal, Gamma ve Log-normal için 17 ağaçlıkörnek alan büyüklüğünün yeterli olduğu görülmüştür. bu sonuçlarda çap dağılımının ortaya koyulmasında en uygunörnek alan büyüklüğünün 17 ağacı kapsayacak örnek alan büyüklüğü olduğu sonucuna varılmıştır.

Genel has 1lat kuralı olarak ormanın ana ürünü olan odun maddesinin oluşumunda etkili olan faktörler yaş, ağaç türü genetik özellikleri, yetişme ortamı faktörleri ve silvikültürel uygulamalar şeklindedir (Kalıpsı, 1982). Sıklık önemli bir meşcere parametresi olup çap dağılımlarında da etkin bir değişkendir. $\mathrm{Bu}$ yüzden çap dağılım modellerinin ortaya koyulmasında sıklığında bir değişken olarak kullanılması gerekir (Doğdaş, 2014). Böylece meşcerelerde çap dağılımının ortaya koyulmasında daha yüksek bir belirtme katsayısı ve F değeri elde edilebilir.

Dağılım fonksiyonlarınıtemel alan regresyon modelleri, hasılat çalışmalarında meşcere simülasyonlarına olanak sağlamaktadır. Meşceredeki bireylerin çap basamaklarına 
dağılımının bilinmesiyle belirli zaman aralıklarında oluşan artımlar daha doğru olarak tahmin edilebilir.

$\mathrm{Bu}$ çalışmada kullanılan veriler geçici nitelikteki örnek alanlardan elde edilmiş tir. Bunun yanında farklı yaş, bonitet ve sıklk derecelerindeki meşcerelerde tesis edilecek devamlı deneme alanlarının oluşturulması ve periyodik olarak ölçülmesi yoluyla çap dağılımı ile birlikte meşcere hacim ve hacim elemanları gerçeğe daha yakın tahmin edilebilir.

\section{Teşekkür}

3964-YL1-14 No'lu Proje ile bu çalışmayı maddi olarak destekleyen SDÜ Bilimsel Araştırma Projeleri Yönetim Birimi Baş kanlığı'na teşekkür ederiz.

\section{Kaynaklar}

Atıcı, E., 1998. Değişik yaşlı Doğu kayını(Fagus orientalis Lipsky.) ormanlarında artım ve büyüme. Doktora Tezi, İstanbul Üniversitesi, Fen Bilimleri Enstitüsü, 386s. İstanbul.

Bailey, R.L., Dell, T.R., 1973. Quantifying diameter distributions with the Weibull function. Forest Science, 19:97-104.

Borders, B.E., Patterson, W.D., 1990. Projecting stand tables: a comparis on of the weibull diameter dis tribution method, a percentile-based projection method. Forest Science, 36:413-424.

Bruce, D., Schumacher, F.X., 1950. Forest Mensuration. McGraw-Hill Book Company, 483p. New York.

Cao, Q.V., 1997. A Method to distribute mortality in diameter distribution models. Forest Science, 43:435442.

Carus S., 1998. Aynı yaşlı Doğu kayını (Fagus orientalis Lipsky.) ormanlarında artım ve büyüme. Doktora Tezi, İstanbul Üniversitesi, Fen Bilimleri Enstitüsü, 359 s, İstanbul

Carus, S., Çatal, Y., 2008. Kızılçam (Pinus brutia Ten.) meşcerelerinde 7-ağaç örnek nokta yöntemiyle meşcere ağaç sayısının çap basamaklarına dağılımının belirlenmesi. Süleyman Demirel Üniversitesi, Orman Fakültesi Dergisi, A(2):158-169.

Clutter, J.I., Bennet, F.A., 1965. Diameter Distributions in Old-Field Slash Pine Plantations. Georgia Forest Research Council Report 13, 9p.

Çatal, Y., 2009. Batı Akdenizbölgesikızılçam (Pinus brutia Ten.) meşcerelerinde artım ve büyüme. Doktora Tezi, Süleyman Demirel Üniversitesi, Fen Bilimleri Enstitüsü, $281 \mathrm{~s}$, Is parta.

Doğdaş, İ., 2014. Burdur-Ağlasun yöresi kızılçam (Pinus brutia Ten.) ormanlarında meşcere ağaç sayısı, hacimve hacim artımının çap basamaklarına dağılımının modellenmesi. Yüksek Lisans Tezi, Süleyman Demirel Üniversitesi Fen Bilimleri Enstitüsü 98s, Isparta.

Ercanl, İ., Yavuz, H., 2010. Doğu ladini (Picea orientalis (L.) Link)-sarıçam (Pinus sylvestris L.) karış1k meşcerelerinde çap dağılımlarının olasılık yoğunluk fonksiyonları ile belirlenmesi. Kastamonu Üniversitesi, Orman Fakültesi Dergisi, 10(1):68-83.

Frrat, F., 1973. Dendrometri. İstanbul Üniversitesi, Orman Fakültesi Yayın No 1800/193, 359s. İstanbul.
Gül, A.U., Misır, M., Misır, N., Yavuz, H., 2005. Calculation of uneven-aged stand structures with the negative exponential diameter distributionand sterba's competition density rule. Forest Ecology and Management, 214:212-220.

Husch, B., Miller, C.I., Beers, T.W., 1963. Forest Mensuration. The Ronald Pres Company, 402pp. New York.

Kahriman, A., Yavuz, H., 2011. Sarçam (Pinus sylvestris L.)-Doğu kayını (Fagus orientalis Lipsky) karışı meşcerelerinde çap dağılımlarının olasılık yoğunluk fonksiyonları ile belirlenmesi. Artvin Çoruh Üniversitesi Orman Fakültesi Dergisi, 12(2):109-125.

Kalıpsı, A., 1982. Orman Has 1lat Bilgisi. İstanbul Üniversitesi, Orman Fakültesi Yayın No 3194/354, 349s. İstanbul.

Lappi, J., Bailey, R.L., 1987. Estimating of the diameter increment function or other tree relations using singlecount samples. Forest Science, 33:725-739.

Lenhart, J.D., 1972. Cubic volume yields for unthinned oldfield loblolly pine plantations in the interior west gulf coastal plain. Texas Forest Research Service, Paper No $14: 46$

Lenhart, J.D., Clutter, J.L., 1971. Cubic-Foot Yield Tables for Old-Field Loblolly Pine Plantations in the Georgia Piedmont. Georgia Forest Research Council Report 22, $13 \mathrm{pp}$.

Lindsay, R., Wood, G.R., Woollons, R.C., 1996. Modelling the diameter distribution of forest stands using the Burr distribution. Journal of Applied Statistics, 23(6):609620.

Loetsch, F., Zöhrer, F., Haller, KE., 1973. Forest Inventory. Cilt 2. BLV Verlagsgesellschaft. 469p. München Bern Wien.

Mc Gree, C.E., Della-Bianca, L., 1967. Diameter Distributions in Natural Yellow Poplar Stands. Forest Service Research Paper SE-25, 7 p.

Merganič, J., Sterba, H., 2006. Characterisation of diameter distribution using the Weibull function: method of moments. European Journal of Forest Research, 125(4):427-439.

Mike, N., Strub, R., Burkhart, H.E., 1975. A Class-InternalFree Method for Obtaining Expected Yield from Diameter Distributions. Forest Science, 30:573-581.

Nelson, T.C., 1964. Diameter Distribution and Growth of Loblolly Pine. Forest Science, 10:105-115.

Nepal, S.N., Somers, G.L., 1992. A Generalized Approach to Stand Table Projection. Forest Science, 38:120-133.

Newton, P.F., Lei, Y., Zhang, S.Y., 2005. Stand-level Diameter Distribution Yield Model for Black Spruce Plantations. Forest Ecology and Management, 209(3):181-192.

Packard, K.C., 2000. Modeling tree diameter distribustions for mixed-species coniferforests in the Northeast United States. Master Thesis, State University Of New York, 129 s., New York.

Saraçoğlu, Ö., 1988. Karadeniz yöresi göknar meşcerelerinde artım ve büyüme. Orman Genel Müdürlügü Yayınları, 312s, Ankara.

Schreuder, T.H., Hafley, W.L., Bennet, F.A., 1979. Yield prediction for un-thinned natural slash pine stands. Forest Science, 25(1):25-30. 
Somers, G.L., Oderwald, R.G., Harms, W.R., Langdon, O.G., 1980. Predicting mortality with a weibull distribution. Forest Science, 26(2):291-300.

Sterba, H., 1975. Assmann's theorie der grundfla" chenhaltung die "Competition Density Rule" det Japaner Kira, Ando und Tadaki. Cbl. f. d. ges. Forstw. 92:46-62.

Yavuz, H., Gül, A.U., Mısır, N., Özçelik, R., Sakıcı, O.E., 2002. Meşcerelerde çap dağılımlarının düzenlenmesi ve bu dağılımlara ilişkin parametreler ile çeşitli meşcere öğeleri arasında ilişkilerin belirlenmesi. Orman Amenajmanında Kavramsal Açılımlar ve Yeni Hedefler Sempozyumu, 18-19 Nisan, İstanbul.
Zarnoch, S.J., Feduccia, D.P., Baldwin, V.C., Dell, T.R., 1991. Growth and Yield Predictions for Thinned and Unthinned Slash Pine Plantations on Cutover Sites in the West Gulf Region. Research Paper SO-264. LA, US Department of Agriculture, Forest Service, Southern Forest Experiment Station, 32p. New Orleans. 